\title{
Impact of Electricity Production Tax on China's Economy, Energy, and Environment: A CGE-Based Study
}

\author{
Yanqin Wang'*, Zhen Dong², Yong Wang², Guanghui Liu', \\ Hongwei Yang ${ }^{1}$, Dongchao Wang ${ }^{1}$ \\ ${ }^{1}$ State Grid Hebei Economic and Technological Research Institute Co., Ltd, Shijiazhuang, China \\ ${ }^{2}$ State Grid Hebei Electric Power Company Co., Ltd, Shijiazhuang, China
}

Received: 11 July 2017

Accepted: 28 December 2017

\begin{abstract}
The global warming caused by massive energy consumption is one of today's most serious global environmental problems. $\mathrm{CO}_{2}$ emissions by the electricity industry in China accounted for $10 \%$ of global $\mathrm{CO}_{2}$ emissions in 2015. This paper studies the impact of different electricity production taxes on China's energy, economy, and environment. Nine electricity tax scenarios with different tax rates and a dynamic recursive computable general equilibrium (CGE) model were created to analyze this issue. The results show that sectorial output in the coal industry is most sensitive to the tax, and that raising the electricity tax will directly increase the price of electricity. Moreover, increasing the electricity production tax will be helpful for achieving the goal of economic transformation, and to reduce energy consumption as well as $\mathrm{CO}_{2}$ emissions. The longer the implementation of changing the tax, the lower the cost of emission reduction will be. Therefore, this paper suggests that China can increase the production tax rate of power enterprises moderately in order to reduce energy consumption and adjust the energy structure.
\end{abstract}

Keywords: computable general equilibrium (CGE) model, electricity production tax, energy consumption, $\mathrm{CO}_{2}$ emission, economic-energy-environmental impact

\section{Introduction}

Global warming caused by the massive emission of greenhouse gases represented by $\mathrm{CO}_{2}$ is one of the most serious global environmental problems today. China is the largest $\mathrm{CO}_{2}$ emissions emitter in the world. In 2015 $\mathrm{CO}_{2}$ emissions were 10.21 billion tons, accounting for about $28 \%$ of global $\mathrm{CO}_{2}$ emissions [1]. Regardless of

*e-mail: hbdwwyq@163.com whether it is from the angle of sustainable development [2] or from responding to climate change, $\mathrm{CO}_{2}$ emission reduction is the most attractive issue in China's economic and social development [3].

The electricity industry is the largest $\mathrm{CO}_{2}$ emission source, and the amount of $\mathrm{CO}_{2}$ emission by the electricity industry in recent years is close to half of the total $\mathrm{CO}_{2}$ emissions in China every year, or about $10 \%$ of the global $\mathrm{CO}_{2}$ emissions in 2015 [4]. Therefore, the $\mathrm{CO}_{2}$ emission reduction in the electricity industry is of great significance for the efforts of global carbon emission reduction. 
As a basic industry, electrical power enterprises have great influence on all of society. Some scholars focus on the development and energy efficiency of electricity industries. For instance, Martins et al. (2011) [5] looked at the Portuguese experience in the application of PPP arrangements in the energy sector, particularly as far as the development of wind power plants is concerned. And the production tax of electric power enterprises is higher than that in other industries [6]. The impact of variation of electricity tax on the power industry and even the whole society cannot be underestimated. Thus, this paper studies the impacts of different electricity taxes on the energy, economy, and $\mathrm{CO}_{2}$ emissions in China.

Much of the research on tax in the electricity industry has focused on carbon tax [7]. Benavente (2016) [8] studied the impact of a carbon tax on the Chilean economy using computable general equilibrium analysis. Descateaux et al. (2016) [9] assessed the life cycle environmental benefits of renewable distributed generation in a context of carbon taxes in the northeastern American electricity market. Vera and Sauma (2015) [10] compared the effects of reducing $\mathrm{CO}_{2}$ emissions of carbon tax and of some energy-efficiency measures in the power sector. Liu et al. (2016) [11] analyzed the effects of power-generating company profits and emissions profiles under different carbon tax scenarios by valuing the specific part of the cost that affects the environment. Gerbelova et al. (2014) [12] examined the cost effectiveness of different evolutions of $\mathrm{CO}_{2}$ taxes under the Emissions Trading System in Europe by 2050. Chen (2005) [13] finds that carbon tax will lead to an increase in recycling rates. Di Cosmo and Hyland (2013) [14] studied carbon tax scenarios and their effects on the Irish energy sector. Meybodi and Behnia (2011) [15] researched the impact of carbon tax on internal combustion engine size selection in a medium-scale CHP system.

A small number of scholars have studied electricity taxes. Song et al. (2017) [16] employed a network slacksbased measure (SBM) model to research the production efficiency and environmental efficiency of China's coalfired power generation industry from 2006 to 2010, under two different tax policies. Cansino et al. (2016) [17] evaluated a tax on electricity consumption using a pricing model to assess economic impacts. Bjertnaes et al. (2008) [18] designed an electricity tax system in the presence of international regulations and multiple public goals. Lu et al. (2011) [19] analysed the impact of Production Tax Credits on the profitable production of electricity from wind in the United States. Cansino et al. [20] provided a comprehensive overview of the main tax incentives used in the EU-27 member states (MSs) to promote green electricity. Nevertheless, few articles have studied the impact of the energy industry tax from a social perspective in which industry is closely related to economic development. The rational production tax of the power industry plays an important role in global warming, economic development, and energy security, as well as carbon emissions trading. Therefore, this paper focuses on the impact of different electricity taxes on the energy, economy, and $\mathrm{CO}_{2}$ emissions in China.

The innovations of this paper are as follows:

1) This paper analyzes the effects of different electricity production taxes in China in order to explore which is the best option for balancing the economy and the environment.

2) This paper establishes a computable general equilibrium (CGE) model to analyze the impact of the tax on the economy, energy, and the environment.

To study the issue, we use the CGE model that can be used to analyze a macro-economic impact. The model is widely used to analyze policy impact, such as Carbone and Rivers' (2017) [21] studies on the impacts of unilateral climate policy on competitiveness and Pui and Othman (2017) [22] examining the impact on economic growth and sectoral performance with fuel subsidy savings being reallocated to the biofuel industry for research and development purposes. In research by Wu et al. (2014) [23], Chinese GDP is estimated using a recursive dynamic CGE model. Kolsuz and Yeldan (2017) [24] studied the synergies between environmental abatement instruments and policies toward sustaining green jobs. Ramberg et al. (2017) [25] evaluated the economic viability of gas-to-liquids technology and its impact on the evolution of the crude oil-natural gas price ratio. This paper establishes a dynamic recursive CGE model and constructs 9 scenarios to analyze the impact of different electricity taxes on energy, the economy, and the environment in China.

\section{Methodology}

\section{CGE Model}

CGE model is widely used in policy analysis [2628]. Constructions of all CGE models are based on the traditional Walras paradigm, which means that the model can be described as a system of simultaneous equations deduced by all actors' maximizing behavior. The CGE model simulates the activity of social subjects like residents, enterprises, government, and foreigners [29-30]. Five blocks make up the CGE model: production, income-expenditure, trade, environment, and macroscopic-closure and market-clearing. The general framework of the CGE model is illustrated in Fig. 1.

CGE assumes that one sector only produces one kind of production by the utilization of factors. And in this block, the output consists of value-added energy (VAE), intermediate input, and policy cost following a Leontief function. VAE is the combination of value-added (VA) and energy following a constant elasticity of substitution (CES) function. The next level is VA bundle and energy bundle, which are constituted by labor and capital, electricity and non-electric (fossil energy), following a CES function, respectively. The non-electric bundle is constituted by coal and non-solid (oil and gas) following a CES function. 


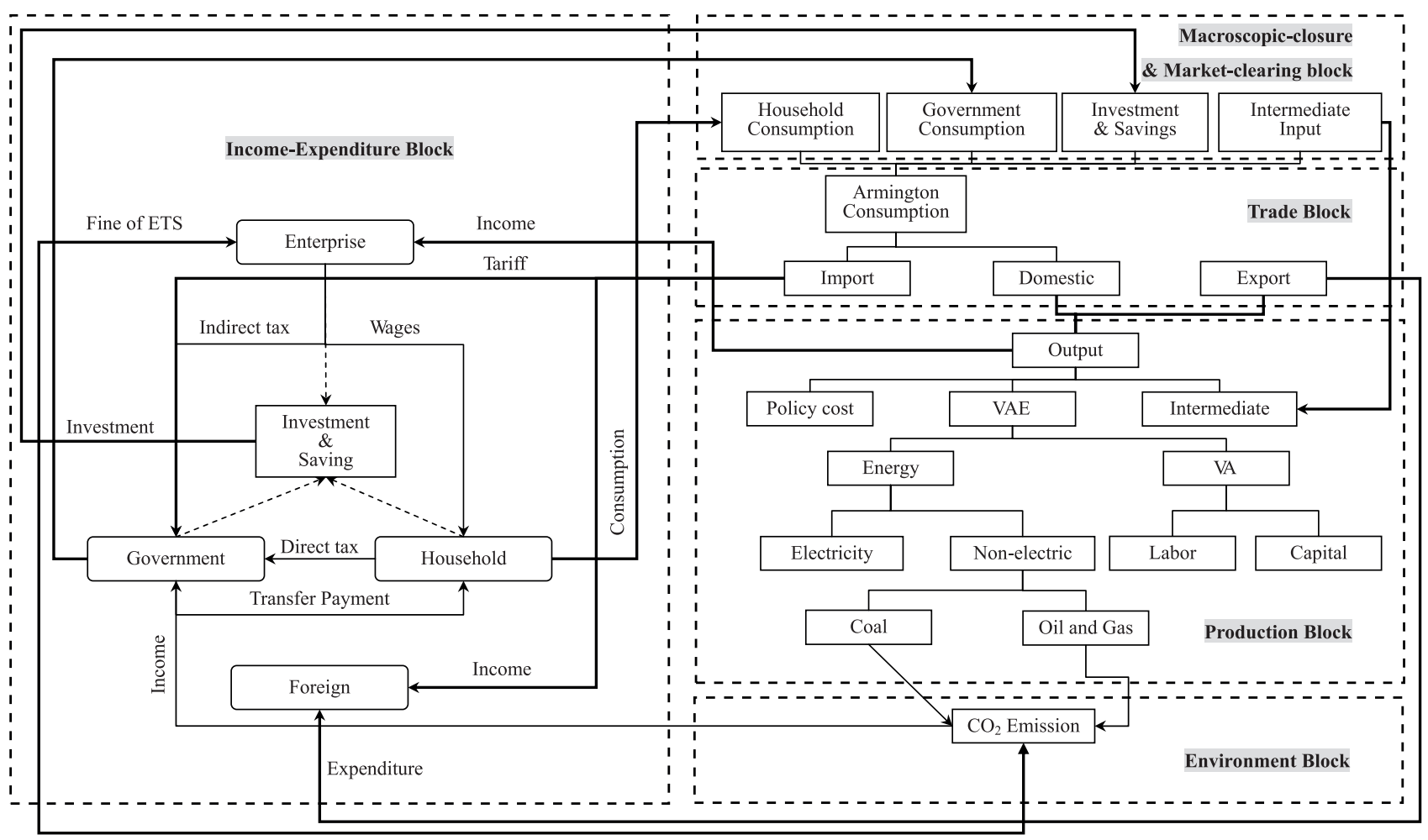

Fig. 1. General framework of the CGE model.2.1.1 production block.

\section{Income-Expenditure Block}

Government, enterprises, households, and foreigners are four subjects in this block, which are important parts of society. The CGE model embodies the balance and relationship of the four subjects. For government, it acquires revenues via direct tax, indirect tax, and tariff; some of these revenues are then used as transfer payments, and others for consumption and saving. For domestic enterprises, they get revenue from consumption by government, resident, and other enterprises to support their own consumption, indirect tax, wages, and saving. For the households, they get money through remuneration from enterprises, and transfer payments by the government to support consumption and direct tax.

\section{Trade Block}

The CGE model assumes that the same industry produces the same production; that is, products produced by the same industry are homogeneous. For a country, however, imports and exports exist at the same time in one type of commodity. Therefore, like the majority of existing studies, the Armington assumption is introduced based on the CGE model [31-32] using the CES and constant elasticity of transformation (CET) functions.

Table 1. The main abbreviations in this paper.

\begin{tabular}{|c|c|c|c|}
\hline Abbreviation & Full name & Abbreviation & Full name \\
\hline ETS & Emissions trading scheme & AEEI & Autonomous energy efficiency improvement \\
\hline VA & Value-added & SAM & Social accounting matrix \\
\hline VAE & Value-added and energy & CGE & Computable general equilibrium \\
\hline CES & Constant elasticity of substitution & WIOD & World input-output database \\
\hline CET & $\begin{array}{c}\text { Constant elasticity of transforma- } \\
\text { tion }\end{array}$ & CM & Counter-measured scenario \\
\hline CO2 & Carbon dioxide & SL & Scenarios of lower electricity tax \\
\hline GDP & Gross domestic product & SH & Scenarios of higher electricity tax \\
\hline CI & Carbon intensity & & \\
\hline
\end{tabular}


Table 2. Descriptions and sector classification.

\begin{tabular}{|c|c|}
\hline Sectors & Description \\
\hline AGR & Agriculture, forestry, animal husbandry, and fishery \\
\hline COL & Coal mining and washing industry \\
\hline O_G & Petroleum and natural gas exploitation \\
\hline PAP & Paper industry \\
\hline CMT & Cement \\
\hline FER & Chemical fertilizer \\
\hline CMC & Chemicals \\
\hline STL & Steel smelting and rolling processing industry \\
\hline EQU & Equipment manufacturing industry \\
\hline ELC & Electricity \\
\hline CST & Construction industry \\
\hline TRA & Transportation \\
\hline OTH & Other industry \\
\hline SER & Service \\
\hline
\end{tabular}

\section{Macroscopic-Closure and Market-Clearing Block}

This model considers 3 principles of market closure: government budget balance, foreign trade balance, and invest-saving balance. This paper assumes that all the savings are transformed into investment, and that total investment equals total savings endogenously; thus, the model is saving-driving. In the market-clearing block, two principles are followed in this model. One is the market of Armington composite commodity. The other is the factor market. The former shows that all Armington commodities are used for consumption, intermediate, and investment without surplus. The latter is that the market could guarantee full employment.

\section{Social Accounting Matrix}

A social accounting matrix is the most basic data of a CGE model and can be made by an input-output table. The 2010 China input-output table is used in this model, and the year 2010 is the base year. The data of SAM is from the China Statistical Yearbook [33] and China input-output table (CIOT) supported by the China Input-

Table 3. Coal equivalent coefficient and $\mathrm{CO}_{2}$ emissions coefficient of fossil energy.

\begin{tabular}{|c|c|c|}
\hline $\begin{array}{c}\text { Primary } \\
\text { energy }\end{array}$ & $\begin{array}{c}\text { Coal equivalent } \\
\text { coefficient of primary } \\
\text { energy }\end{array}$ & $\begin{array}{c}\mathrm{CO}_{2} \text { emissions } \\
\text { coefficient of primary } \\
\text { energy }\end{array}$ \\
\hline Coal & $0.743 \mathrm{~kg} / \mathrm{kg}$ & $1.852 \mathrm{~kg} / \mathrm{kg}$ \\
\hline Oil & $1.429 \mathrm{~kg} / \mathrm{kg}$ & $3.561 \mathrm{~kg} / \mathrm{kg}$ \\
\hline Gas & $1.330 \mathrm{~kg} / \mathrm{m}^{3}$ & $3.316 \mathrm{~kg} / \mathrm{m}^{3}$ \\
\hline
\end{tabular}

Table 4. Population growth 2010-2030.

\begin{tabular}{|c|c|}
\hline Year & Population growth rate \\
\hline $2010-2015$ & $0.61 \%$ \\
\hline $2016-2020$ & $0.61 \%$ \\
\hline $2021-2025$ & $0.20 \%$ \\
\hline $2026-2030$ & $0.14 \%$ \\
\hline
\end{tabular}

Output Association (CIOA) [34]. The SAM is balanced through using the SG-RAS method [35]. Two points are worth mentioning in this paper: the first is that the price in this paper has been discounted into the present value of 2010, the second is that this paper discusses the carbon dioxide emissions only from fossil fuels used for society - not related to microbial decomposition and animal and plant respiration. The China input-output table includes 42 sectors. In order to highlight the key point of the research, we reclassified the industry. We divided the whole country into 14 departments that consist of energy sectors (such as coal, electricity) and energy-intensive sectors (such as steel, equipment), which is shown in Table 2. Coal equivalent coefficient and $\mathrm{CO}_{2}$ emission coefficients of fossil energy are shown in Table 3.

\section{Model Dynamics}

Capital depreciation is determined by capital stock of current period and investment. Capital stock is endogenous except for the first period, and investment is endogenous. Labor endowment is exogenous and determined by the National Population Development Strategy Research Report [36] (see Table 4). Autonomous energy efficiency improvement (AEEI) in the CGE model is considered in this study. According to Medium and Long-term Energy Saving Special Planning [37] and the set of Lin and Jia (2018) [38], the energy consumption level of energy-intensive industries in China will nearly reach the international advanced level in the year 2020. AEEI assumed in this paper is shown in Table 5.

\section{Scenario Design}

The production tax on electricity industry is $5.36 \%$ according to CIOA. The mathematical expressions of production tax translated into the CGE model are $\tau_{i}^{z}$, and

Table 5. Autonomous energy efficiency improvement of each sector ${ }^{\mathrm{a}}$.

\begin{tabular}{|c|c|c|c|c|c|c|c|}
\hline Sectors & AGR & COL & O_G & PAP & CMT & FER & CMC \\
\hline AEEI & 0.025 & 0.006 & 0.006 & 0.015 & 0.015 & 0.02 & 0.015 \\
\hline Sectors & STL & EQU & ELC & CST & TRA & OTH & SER \\
\hline AEEI & 0.025 & 0.03 & 0.025 & 0.006 & 0.033 & 0.016 & 0.023 \\
\hline
\end{tabular}

${ }^{a}$ The AEEI will be halved after 2020. 
Table 6. Scenario design.

\begin{tabular}{|c|c|}
\hline Scenario & The variation of electricity tax \\
\hline S-100 & $-100 \%$ \\
\hline S-30 & $-30 \%$ \\
\hline S-20 & $-20 \%$ \\
\hline S-10 & $-10 \%$ \\
\hline S & $0 \%$ \\
\hline S10 & $+10 \%$ \\
\hline S20 & $+20 \%$ \\
\hline S30 & $+30 \%$ \\
\hline S100 & $+100 \%$ \\
\hline
\end{tabular}

the rate of electricity tax is $\tau_{\text {elc }}^{z}$. This paper establishes a business-as-usual scenario and eight countermeasure scenarios to simulate the changes in electricity tax (Table 6). In $\mathrm{S}$ scenario, the electricity tax rate remains unchanged. In S-30, S-20, and S-10 scenarios, the tax rates are $30 \%, 20 \%$, and $10 \%$ lower than that in S scenario, respectively. S-100 scenario simulates the abolition of the electricity tax. The tax rates in S10, S20, S30, and S100 scenarios are $10 \%, 20 \%, 30 \%$, and $100 \%$ greater than in $\mathrm{S}$ scenario, respectively. And we assume that the change of electricity tax will begin in 2017.

\section{Results and Discussion}

Economic Impact

$G D P$

Gross domestic product (GDP) in S scenario during 2010 to 2030 is illustrated in Fig. 2. GDP will rise from $\$ 5.90$ billion US in 2010 to $\$ 12.41$ billion in 2030 (note that the GDP depicted here is real GDP instead of the nominal one). The annual growth rate is between $3.17 \%$ and $6.37 \%$. The trend of GDP growth basically coincides with Higgins et al. (2016) [38] and Pao et al. (2012) [39].

The variation of GDP in all scenarios compared with S scenario during 2017-2030 is illustrated in Fig. 3. In

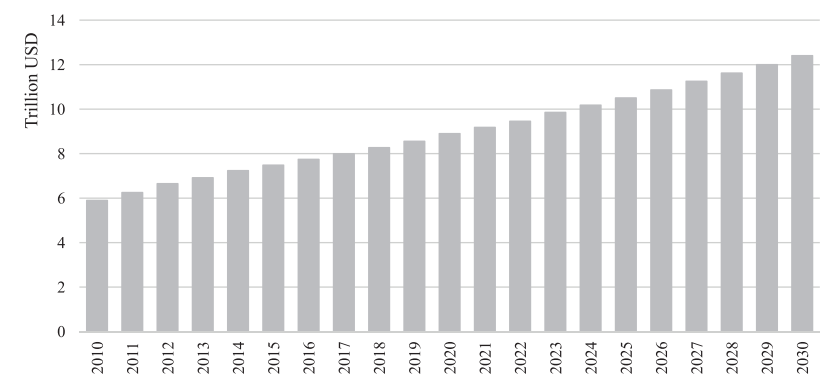

Fig. 2. GDP in S scenario during 2010 to 2030.



Fig. 3. GDP variation in all scenarios compared with S scenario during 2017-2030.

2017 GDP will increase in S-30, S-20, and S-10 scenarios compared with S scenario by $0.08 \%, 0.05 \%$, and $0.03 \%$, respectively, while GDP in S100, S30, S20, and S10 scenarios will decrease. Although abolishing electricity tax will have a relatively strong positive impact on GDP in the short term, the impact will continue to decline and become negative in 2029 . We find that relaxation of the tax on electricity will promote the growth of GDP, while raising the tax on electricity will have a negative impact on GDP. But the two kinds of influences will become smaller as time goes by. The reason why the impact will be smaller as time goes by might be that 1) resource allocation has gradually become more reasonable, so that the negative impact of the increase in electricity tax on GDP is gradually reduced, 2) while lowering the tax on electricity will curb the sustainable development and industrial restructuring, so the GDP growth rate will be gradually reduced.

\section{Sectorial Output}

The variation of sectorial output in all scenarios compared with S scenario in 2030 is illustrated in Fig. 4. The output of COL, O_G, and ELC industries in the tax relaxation scenario will increase by 1.14$12.34 \%, 0.64-6.70 \%$, and $0.98-10.55 \%$, respectively. Other industries will increase their output by $0.02-1.59 \%$. The scenarios of increasing electricity tax will have opposite results. We can find that industry most affected by the electricity tax is coal. Then the second most sensitive industry is electricity, and the third is oil and gas. The output of construction will hardly be affected. The main reason why coal is the most sensitive industry may be that more than $60 \%$ of generating capacity is from coal-fired power plants. Moreover, the electricity industry is the biggest buyer of coal. The change of electricity tax will directly lead to the output of power enterprises and the decision of purchase, which will influence the sales of coal enterprises. The most flexible enterprises on the electricity tax are the energy industries, which means that the tax on electricity can directly affect energy consumption of the whole country. The importance of the electricity tax is reflected here. 


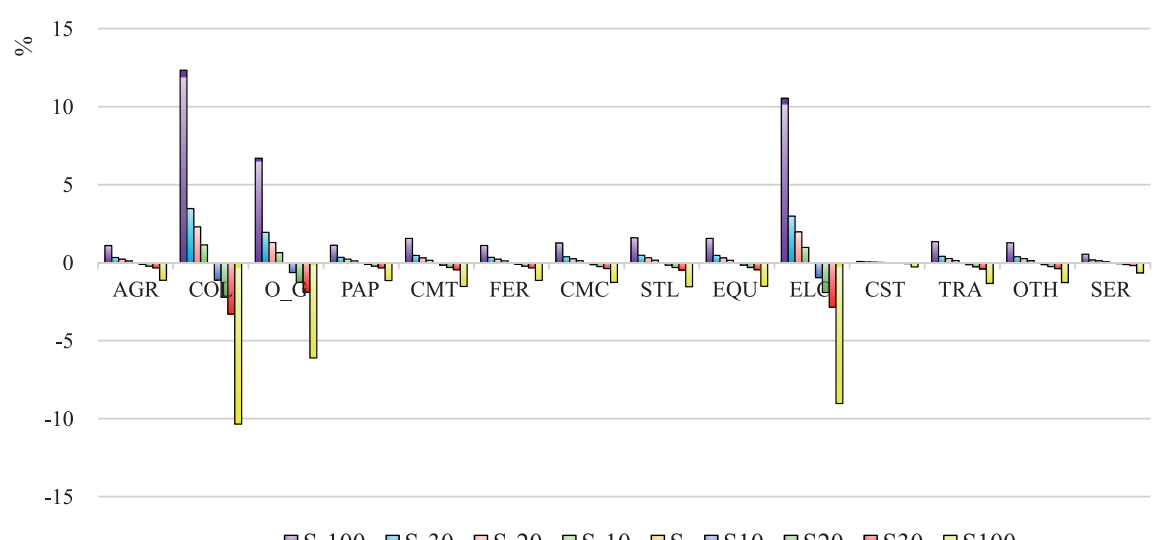

$\square \mathrm{S}-100 \quad \square \mathrm{S}-30 \quad \square \mathrm{S}-20 \quad \square \mathrm{S}-10 \quad \square \mathrm{S} \quad \square \mathrm{S} 10 \quad \square \mathrm{S} 20 \quad \square \mathrm{S} 30 \quad \square \mathrm{S} 100$

Fig. 4. Variation of sectorial output in all scenarios compared with S scenario in 2030.

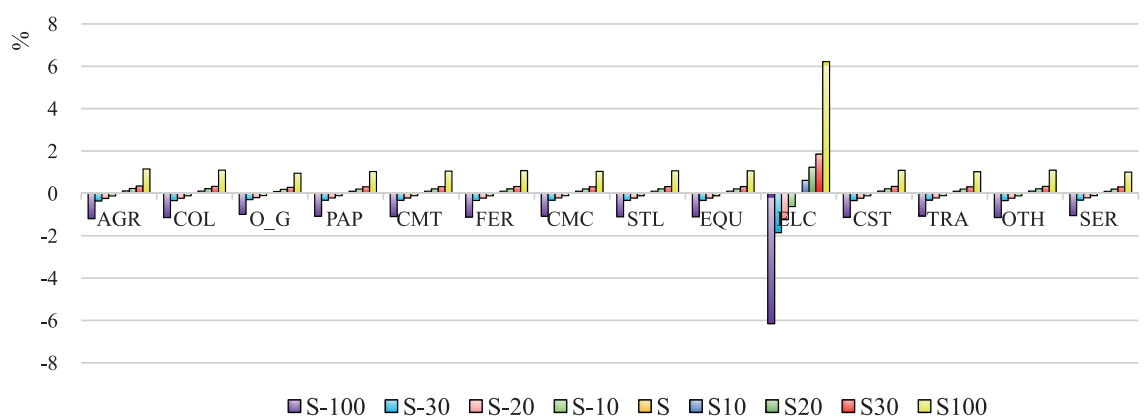

Fig. 5. Variation of commodity pricing in all scenarios compared with S scenario in 2030.

\section{Commodity Price}

The variation of commodity price in all scenarios is compared with S scenario in 2030. In SL scenarios, commodity price will be reduced compared with $\mathrm{S}$ scenario, while it will rise in SH scenarios. The greater the change in electricity tax, the greater the change in the price of goods. The price of electricity in SL and SH scenarios will increase from $-0.62 \%$ to $-0.615 \%$ and from $0.11 \%$ to $1.07 \%$, respectively. Other commodity prices will change within $1.19 \%$. The rise of electricity tax will directly increase the cost of the electrical industry, and then the cost will be reflected in price.
After that, the increasing electricity price will lead the cost and the price of other industries higher. Therefore, the rise in other commodity prices is due to the rise of electricity price. We can find that although the tax on electricity has a significant impact on the consumption of energy commodities, its impact on the prices of other commodities, except electricity, will not be significant.

\section{Import and Export}

The variation of import in all scenarios compared with S scenario in 2030 is illustrated in Fig. 6. The import in all sectors except for electricity and construction will

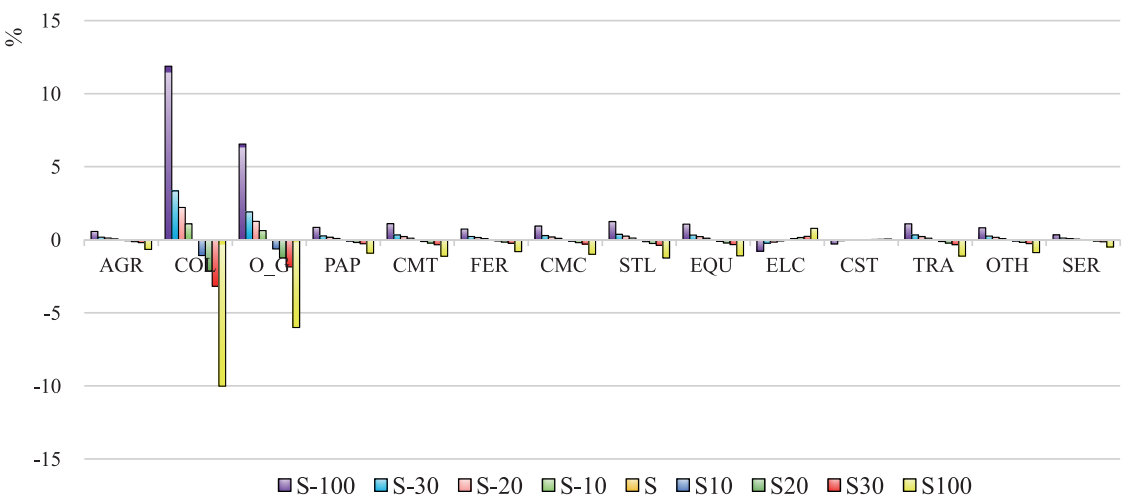

Fig. 6. Variation of import in all scenarios compared with S scenario in 2030. 


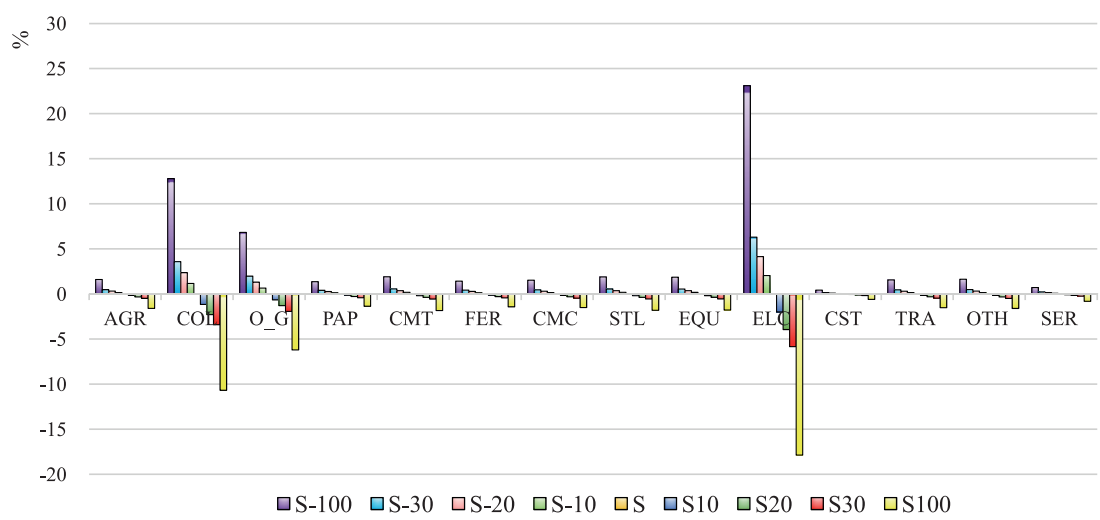

Fig. 7. Variation of export in all scenarios compared with S scenario in 2030.



Fig. 8. Flow of labor in all scenarios compared with S scenarios in 2030.

increase in SL scenarios, while it will decrease in SH scenarios. Coal import is most sensitive to electricity tax, the next is oil. However, the changes in electricity tax will have little impact on electricity imports. The main reason why the imports of fossil energy will decrease by increasing electricity tax may be that the reduction of electricity demand will reduce fossil energy consumption as well as the import of fossil energy.

The variation of export in all scenarios compared with S scenario in 2030 is depicted in Fig. 7. The export of electricity is most sensitive to electricity tax, which will change from $-17.86 \%$ to $23.11 \%$. The next is COL and $\mathrm{O} \_\mathrm{G}$, by $-10.68 \%$ to $12.80 \%$ and $6.21 \%$ to $6.84 \%$, respectively. The variation of export in other industries will be no more than $2 \%$. The reason why the exports of energy production will decrease by increasing electricity tax may be that the tax will lead the price of energy production rise (the commodity price is introduced in section 4.1.3), so that the international competitiveness of domestic production of fossil energy and electricity will be lower in SH scenarios than in SL scenarios.

\section{Labor Mobility}

The flow of labor in all scenarios compared with $\mathrm{S}$ scenarios in 2030 is illustrated in Fig. 8. The labor force in electric power enterprises will be lost greatly with the increasing electricity tax. COL and $\mathrm{O}_{-} \mathrm{G}$ industries will also lose labor enforcement when the electricity tax rises, by $0.15-1.64 \%$ and $0.09-0.95 \%$, respectively. All other industry will absorb these outflows of labor. Among them, the labor in service will grow greater than others, which will absorb about $61 \%$ of the outflow labor force. We find that the increasing electricity tax will significantly shift the labor force from the energy sector to the service sector, which will be helpful for China to achieve the goal of economic transformation. However, reducing the electricity tax will spur energy industries to transform into labor-intensive enterprises.

\section{Energy Impact}

\section{Fossil Energy}

Fossil energy consumption in all scenarios in 2030 is shown in Fig. 9. Coal, oil, and gas consumption in the $2030 \mathrm{~S}$ scenario will be 3.99 billion tons of coal equivalent (TCE) and 1.08 billion TCE, respectively. And the rate of coal consumption is $78.70 \%$. In the S100 scenario, coal consumption will be 3.58 billion TCE, and oil and gas consumption will be 1.01 billion TCE. The increase of electricity tax will reduce coal consumption as well as the consumption of oil and gas. The rate of coal consumption will also be reduced in SH scenarios. The performance is entirely reversed in SL scenarios. In other words, the increasing electricity tax will reduce energy 


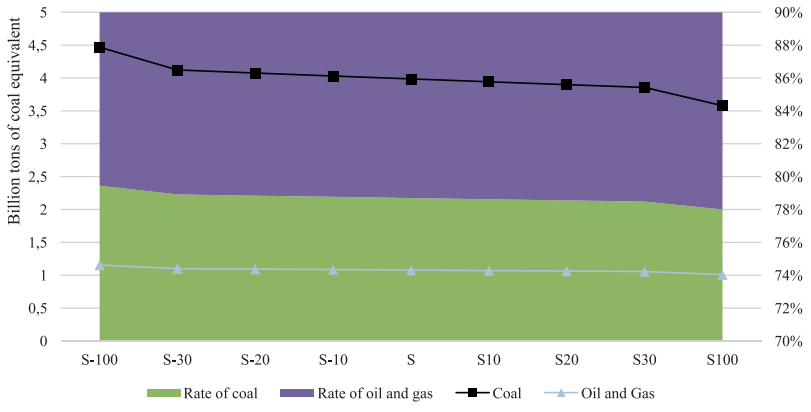

Fig. 9. Fossil energy consumption in all scenarios in 2030.

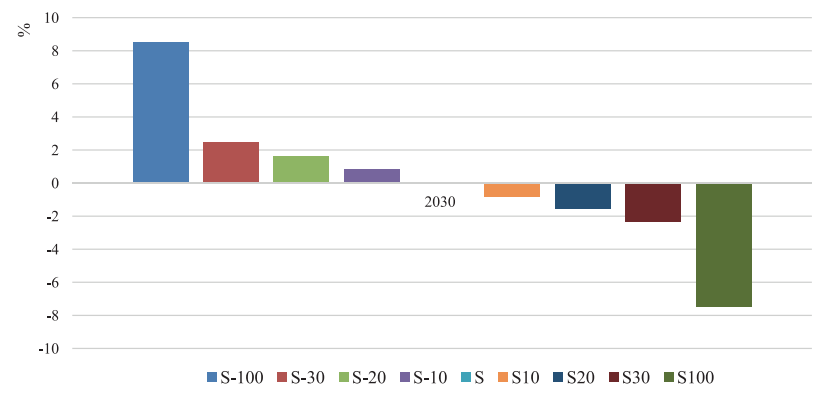

Fig. 10. Variation of electricity consumption in all scenarios in 2030 .

consumption and will optimize the energy structure to a certain extent. The increasing tax on electricity will reduce coal consumption indirectly but significantly, as well as oil and gas consumption. And the reduction of fossil energy consumption will directly promote the $\mathrm{CO}_{2}$ emission reduction, which will be introduced in a later section.

\section{Electricity}

The variation of electricity consumption in all scenarios in 2030 is illustrated in Fig. 10. The relaxation of the electricity tax will directly promote the consumption of electricity. With a tax cut of $10 \%$, electricity consumption will rise by about $0.8 \%$, while with an additional tax on electricity, electricity consumption will be reduced by about $0.8 \%$. We also find the law of diminishing marginal returns: for each additional $10 \%$ of electricity tax, the amount of reduced electricity consumption will be reduced. Moreover, the reduced electricity consumption will lead to a reduction in fossil energy used.

\section{Environmental Impact \\ Carbon Emission Intensity}

Carbon emission intensity (CI) in all scenarios during 2017-2030 is depicted in Fig. 11. In S scenario, $\mathrm{CI}$ will be reduced from $116.96 \mathrm{~kg}-\mathrm{CO}_{2} /$ thousand USD in 2017 to $101.76 \mathrm{~kg}-\mathrm{CO}_{2} /$ thousand USD in 2030. In the S-100 scenario, CI is bigger than other scenarios, by $113.03-129.44 \mathrm{~kg}-\mathrm{CO}_{2} /$ thousand USD. While CI in S100 scenarios is less than other scenarios by 92.36-106.48 $\mathrm{kg}-\mathrm{CO}_{2} /$ thousand USD. The electricity tax can significantly affect CI. That is to say, the more electricity tax, the less CI. The main reason is that the electricity tax has an obvious positive impact on reducing fossil energy consumption, which could promote the reduction of CI. The reason why CI is lower in SL scenarios than other scenarios is that emission reduction is greater than GDP loss in SL scenarios, that is, the elasticity of electricity tax on $\mathrm{CO}_{2}$ emissions is greater

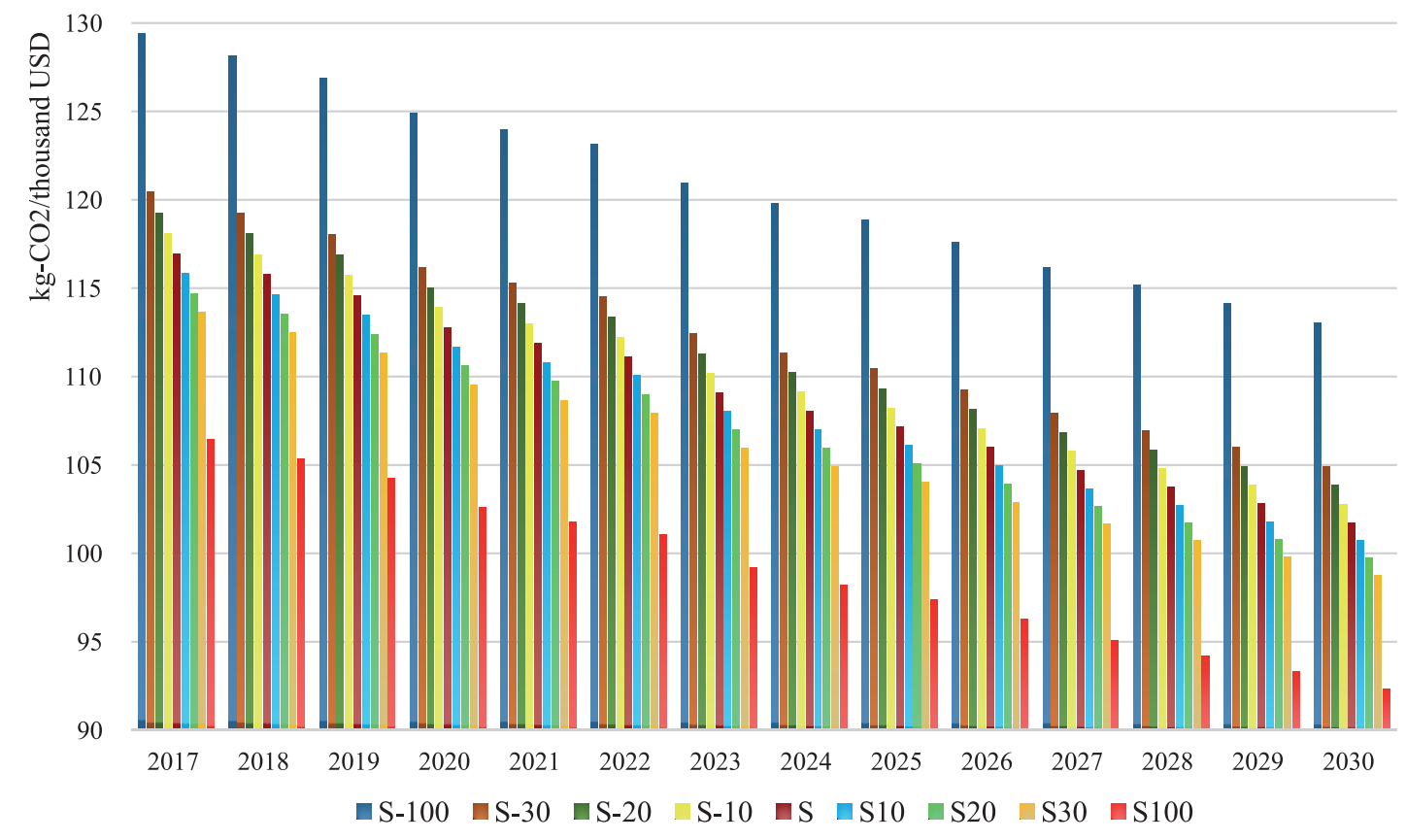

Fig. 11. Carbon emission intensity in all scenarios during 2017-2030. 
Table 7. Reduction cost in all scenarios during 2017-2030 (USD/t- $\mathrm{CO}_{2}$ ).

\begin{tabular}{|c|c|c|c|c|c|c|c|c|c|}
\hline \multirow{2}{*}{ Year } & \multicolumn{4}{|c|}{ SL scenarios } & \multirow{2}{*}{ S } & \multicolumn{4}{|c|}{ SH scenarios } \\
\cline { 2 - 6 } \cline { 7 - 9 } & S-100 & S-30 & S-20 & S-10 & & S10 & S20 & S30 & S100 \\
\hline 2017 & 16.51 & 21.62 & 22.32 & 23.02 & 0.00 & 24.40 & 25.09 & 27.57 & 30.36 \\
\hline 2018 & 15.47 & 20.75 & 21.48 & 22.20 & 0.00 & 23.63 & 24.34 & 25.05 & 29.78 \\
\hline 2019 & 14.35 & 19.80 & 20.56 & 21.30 & 0.00 & 22.78 & 23.51 & 24.24 & 29.13 \\
\hline 2020 & 13.20 & 18.87 & 19.66 & 20.43 & 0.00 & 21.97 & 22.72 & 23.48 & 28.56 \\
\hline 2021 & 11.99 & 17.83 & 18.64 & 19.44 & 0.00 & 21.02 & 21.80 & 22.58 & 27.81 \\
\hline 2022 & 10.67 & 16.69 & 17.52 & 18.34 & 0.00 & 19.97 & 20.77 & 21.58 & 26.96 \\
\hline 2023 & 9.38 & 15.65 & 16.51 & 17.37 & 0.00 & 19.06 & 19.90 & 20.74 & 26.34 \\
\hline 2024 & 7.89 & 14.36 & 15.25 & 16.14 & 0.00 & 17.89 & 18.75 & 19.61 & 25.39 \\
\hline 2025 & 6.28 & 12.95 & 13.87 & 14.79 & 0.00 & 16.59 & 17.48 & 18.37 & 24.33 \\
\hline 2026 & 4.57 & 11.48 & 12.43 & 13.38 & 0.00 & 15.24 & 16.16 & 17.08 & 23.23 \\
\hline 2027 & 2.75 & 9.91 & 10.89 & 11.87 & 0.00 & 13.80 & 14.75 & 15.70 & 22.07 \\
\hline 2028 & 0.79 & 8.18 & 9.20 & 10.20 & 0.00 & 12.19 & 13.18 & 14.16 & 20.73 \\
\hline 2029 & -1.30 & 6.33 & 7.38 & 8.42 & 0.00 & 10.48 & 11.49 & 12.51 & 19.29 \\
\hline 2030 & -3.53 & 4.36 & 5.44 & 6.52 & 0.00 & 8.64 & 9.69 & 10.74 & 17.74 \\
\hline
\end{tabular}

than that on GDP. This result suggests that we could reduce $\mathrm{CO}_{2}$ emissions and $\mathrm{CI}$ by increasing the electricity tax, or reducing the subsidy to electricity industries.

\section{Reduction Cost}

Reduction cost in all scenarios during 2017-2030 is shown in Table 7. The reduction cost this paper discussed is the ratio of GDP to emission reduction, which represents the cost of GDP that must be paid for emission reduction. In $\mathrm{SH}$ scenarios, the reduction cost will decrease as time goes by. For instance, the cost is $24.40 \mathrm{USD} / \mathrm{t}-\mathrm{CO}_{2}$ in the $2017 \mathrm{~S} 10$ scenario, and it will be $10.48 \mathrm{USD} / \mathrm{t}-\mathrm{CO}_{2}$ in 2030. Moreover, the higher the electricity tax, the greater the reduction cost.

As for SL scenarios, reduction cost means the amount of GDP that can be increased by an additional unit of $\mathrm{CO}_{2}$ emission. So it is not like SH scenarios that the higher the reduction cost, the better to society. Although we can find that the costs perform well in the short term, the benefits of GDP growth from increasing carbon dioxide emissions are getting smaller as time goes by. For example, the reduction cost is $23.02 \mathrm{USD} / \mathrm{t}-\mathrm{CO}_{2}$ in $2017 \mathrm{~S}-10$ scenario while it will be $6.52 \mathrm{USD} / \mathrm{t}-\mathrm{CO}_{2}$ in 2030. Furthermore, in the S-100 scenario, the value of reduction cost will be negative in 2029 and 2030. We find that raising the electricity tax will have long-term interests in reducing emissions. Nevertheless, reducing the electricity tax is not the choice of long-term interests.

\section{Conclusion}

This paper establishes 9 electricity tax scenarios with different rates of tax, and constructs a dynamic recursive computable general equilibrium model to analyze the impact of different electricity taxes on GDP, sectorial output, commodity price, international trade, labor mobility, fossil energy consumption, electricity consumption, carbon emission intensity, and reduction cost. And, finally, this paper arrives at the following conclusions.

The relaxation of the tax on electricity will promote the growth of GDP, while raising the tax will have a negative impact on GDP. However, the impact of electricity tax on GDP will gradually decrease from 2017-2030. Sectorial output in the coal industry is most sensitive to the tax, the main reason being that the rising electricity tax will guide the purchase decision of electric power enterprise and finally lower the income of the coal industry. The rise of electricity tax will directly increase the cost of the power industry, then the cost will be reflected in electricity prices. The imports and exports on fossil energy will decrease by rising electricity tax. The main reason is the two aspects of price and demand. The increasing of the electricity tax will significantly push the labor force outflow from the energy industries, such as coal and electricity, to the service industry, which will be helpful for China to achieve the goal of economic transformation. Also, increasing the electricity tax will reduce energy consumption and optimize the energy structure to a certain extent. Moreover, the more electricity tax, the less CI. And the rise of the electricity tax will have long-term interests in reducing emissions. As time goes on, the cost of emission reduction will gradually decrease.

Thus, this paper strongly suggests that we can reduce $\mathrm{CO}_{2}$ emissions by increasing the electricity tax by $10-30 \%$ in order to reduce energy consumption and adjust energy structure. Carbon emission intensity can be reduced significantly by increasing carbon intensity. Also, increasing the electricity tax will be helpful in 
achieving the goal of economic transformation, and to reduce energy consumption as well as $\mathrm{CO}_{2}$ emissions. The longer the implementation of the policy, the lower the cost of emissions reduction.

Another reason why increasing the electricity tax is highly recommended to reduce $\mathrm{CO}_{2}$ emissions in this paper is that it may be much easier to achieve emissions reduction by means of a mature commodity market than a carbon trading market or carbon tax. We can use a small amount of government resources to complete the task. Why do we have to spend a lot of social resources?

\section{Appendix A. Equation system of the dynamic CGE model}

\begin{tabular}{|c|c|}
\hline \multicolumn{2}{|c|}{ A. 1 Production block } \\
\hline$N O E_{i}=\alpha_{i}^{n o e}\left[\delta_{i}^{n o e} C O A L_{i}^{\rho_{i}^{n o e}}+\left(1-\delta_{i}^{n o e}\right) N O S_{i}^{\rho_{i}^{n o e}}\right]^{1 / \rho_{i}^{n o e}}$ & (A.1) \\
\hline$\underline{P C O A L_{i}}=\underline{\delta_{i}^{n o e}}\left(\operatorname{NOS}_{i}\right)^{\left(1-\rho_{i}^{\text {noe }}\right)}$ & (A.2) \\
\hline$\overline{P N O S_{i}}-\overline{1-\delta_{i}^{\text {noe }}}\left(\overline{C O A L_{i}}\right)$ & (11.2) \\
\hline$N O E_{i} P N O E_{i}=C O A L_{i} P C O A L_{i}+N O S_{i} P N O S_{i}$ & (A.3) \\
\hline$E N E_{i}=\alpha_{i}^{\text {ene }}\left[\delta_{i}^{\text {ene }} E L E_{i}^{\rho_{i}^{\text {ene }}}+\left(1-\delta_{i}^{\text {ene }}\right) N O E_{i}^{\rho_{i}^{\text {ene }}}\right]^{1 / \rho_{i}^{\text {ene }}}$ & (A.4) \\
\hline$\frac{P E L E_{i}}{P N O E_{i}}=\frac{\delta_{i}^{\text {ene }}}{1-\delta_{i}^{\text {ene }}}\left(\frac{N O E_{i}}{E L E_{i}}\right)^{\left(1-\rho_{i}^{\text {ene }}\right)}$ & (A.5) \\
\hline$E N E_{i} P E N E_{i}=E L E_{i} P E L E_{i}+N O E_{i} P N O E_{i}$ & (A.6) \\
\hline$V A_{i}=\alpha_{i}^{v a}\left[\delta_{i}^{v a} L A B_{i}^{\rho_{i}^{v a}}+\left(1-\delta_{i}^{v a}\right) C A P_{i}^{\rho_{i}^{v a}}\right]^{1 / \rho_{i}^{v a}}$ & (A.7) \\
\hline$\left.\underline{P L A B_{i}}=\frac{\delta_{i}^{v a}}{\left(C A P_{i}\right.}\right)^{\left(1-\rho_{i}^{v a}\right)}$ & (A 8) \\
\hline$\overline{P C A P_{i}} \overline{1-\delta_{i}^{v a}}\left(\overline{L A B_{i}}\right)$ & \\
\hline$V A_{i} P V A_{i}=L A B_{i} P L A B_{i}+C A P_{i} P C A P_{i}$ & (A.9) \\
\hline$V A E_{i}=\alpha_{i}^{v a e}\left[\delta_{i}^{v a e} V A_{i}^{\rho_{i}^{v a e}}+\left(1-\delta_{i}^{v a}\right) E N E_{i}^{\rho_{i}^{v a e}}\right]^{1 / \rho_{i}^{\text {vae }}}$ & (A.10) \\
\hline$P V A_{i}-\delta_{i}^{\text {vae }}\left(E N E_{i}\right)^{\left(1-\rho_{i}^{v a e}\right)}$ & (A 11) \\
\hline PENE $_{i} \quad 1-\delta_{i}^{\text {vae }}\left(V A_{i}\right)$ & \\
\hline$V A E_{i} P V A E_{i}=E N E_{i} P E N E_{i}+V A_{i} P V A_{i}$ & (A.12) \\
\hline$I N T_{i, j}=a_{i, j}^{I N T} Z_{j}$ & (A.13) \\
\hline$F V A E_{j}=a_{j}^{V A E} Z_{j}$ & (A.14) \\
\hline$P Z_{j}=a_{j}^{v a e} P V A E+\sum a_{i, j}^{I N T} P Q_{i}$ & (A.15) \\
\hline
\end{tabular}




\begin{tabular}{|l|l|}
\hline \multicolumn{1}{|c|}{ A.2 Income-expenditure block } \\
\hline$S P=s S^{p} \sum_{i}\left(P C A P_{i} \cdot C A P_{i}+P L A B_{i} \cdot L A B_{i}\right)$ & \\
\hline$S G=s s^{g}\left(T D+\sum_{i} T Z_{i}+\sum_{i} T M_{i}\right)$ & \\
\hline$X G_{i}=\frac{\mu_{i}}{P Q_{i}}\left(T D+\sum_{i} T Z_{i}+\sum_{i} T M_{i}-S G\right)$ & \\
\hline$X P_{i}=\frac{\beta_{i}^{x p}}{P Q_{i}}\left(\sum_{i}\left(P C A P \cdot C A P_{i}+P L A B \cdot L A B_{i}\right)-S P-T D\right)$ \\
\hline$T D=\tau^{d} \sum_{i}\left(L A B_{i} \cdot P L A B+C A P_{i} \cdot P C A P\right)$ \\
$T Z_{i}=\tau^{z} P Z_{i} Z_{i}$ \\
\hline$T M_{i}=\tau^{m} P M_{i} M_{i}$ & \\
\hline
\end{tabular}

\begin{tabular}{|l|l|}
\hline \multicolumn{2}{|c|}{ A.3 Trade block } \\
\hline$P E_{i}=\varepsilon P W E_{i}$ & \\
\hline$P M_{i}=\varepsilon P W M_{i}$ & (A.23) \\
\hline$\sum_{i} P W E_{i} E_{i}+S F=\sum_{i} P W M_{i} M_{i}$ & (A.24) \\
\hline$Q_{i}=\gamma_{i}\left(\delta m_{i} M_{i}^{\eta_{i}}+\delta d_{i} D_{i}^{\eta_{i}}\right)^{1 / \eta_{i}}$ & (A.25) \\
\hline$M_{i}=\left[\frac{\gamma_{i}^{\eta_{i}} \delta m_{i} P Q_{i}}{\left(1+\tau_{i}^{m}\right) P M_{i}}\right]^{\frac{1}{1-\eta_{i}}} Q_{i}$ & (A.26) \\
\hline$D_{i}=\left[\frac{\gamma_{i}^{\eta_{i}} \delta d_{i} P Q_{i}}{P D_{i}}\right]^{\frac{1}{1-\eta_{i}}} Q_{i}$ & (A.27) \\
\hline$Z_{i}=\theta_{i}\left(\xi e_{i} E_{i}^{\phi_{i}}+\xi d_{i} D_{i}^{\phi_{i}}\right)^{\frac{1}{\phi_{i}}}$ & \\
\hline$E_{i}=\left[\frac{\theta_{i}^{\phi_{i}} \xi e_{i}\left(1+\tau_{i}^{z}\right) P Z_{i}}{P E_{i}}\right]^{\frac{1}{1-\phi_{i}}} Z_{i}$ & \\
\hline$D_{i}=\left[\frac{\theta_{i}^{\phi_{i}} \xi d_{i}\left(1+\tau_{i}^{z}\right) P Z_{i}}{P D_{i}}\right]^{\frac{1}{1-\phi_{i}}} Z_{i}$ &
\end{tabular}




\begin{tabular}{|c|c|}
\hline \multicolumn{2}{|c|}{ A.4 Environment block } \\
\hline (II) & (A.32) \\
\hline$C O A L_{i}=\chi_{i}^{\text {coal }} \times E N E E_{-} C O A L_{i}$ & (A.33) \\
\hline$N O S_{i}=\chi_{i}^{n o s} \times E N E{ }_{-} O_{-} G_{i}$ & (A.34) \\
\hline
\end{tabular}

\section{Conflict of Interest}

The authors declare no conflict of interest.

\section{References}

1. GLOBAL CARBON PROJECT. National Carbon Emission 2016-vl.0. Available online: http://www. globalcarbonproject.org/carbonbudget/16/data.htm (accessed 07/2017).

2. CRUZ N., FERREIRA S., CABRAL M., SIMÕES P., MARQUES, R. Packaging waste recycling in Europe: is the industry paying for it? Waste Management. 34 (2), 298, 2014. DOI: $10.1016 /$ j.wasman.2013.10.035

3. LIN B.Q., JIA, ZJ. The impact of Emission Trading Scheme (ETS) and the choice of coverage industry in ETS: A case study in China. Applied Energy. 205, 1512, 2017. DOI: 10.1016/j.apenergy.2017.08.098

4. NATIONAL BUREAU OF STATISTICS. China Energy Statistics Yearbook. Available online: http://cyfd.cnki.com. cn/N2015110114.htm (accessed 07/2017).

5. MARTINS A.C., MARQUES R.C., CRUZ C.O. Publicprivate partnerships for wind power generation: The Portuguese case. Energy Policy. 39 (1), 94, 2011. DOI: 10.1016/j.enpol.2010.09.017

6. NATIONAL BUREAU OF STATISTICS. China Statistics Yearbook. Available online: http://www.stats.gov.cn/tjsj/ ndsj/ (accessed 07/2017).

7. FREEMAN G.M., DRENNEN T.E., WHITE A.D. Can parked cars and carbon taxes create a profit? The economics of vehicle-to-grid energy storage for peak reduction. Energy Policy. 106, 183, 2017. DOI: 10.1016/j. enpol.2017.03.052

8. BENAVENTE J.M.G. Impact of a carbon tax on the Chilean economy: A computable general equilibrium analysis. Energy economics. 57, 106, 2016. DOI: 10.1016/j. eneco.2016.04.014

9. DESCATEAUX P., ASTUDILLO M.F., BEN AMOR M. Assessing the life cycle environmental benefits of renewable distributed generation in a context of carbon taxes: The case of the Northeastern American market. Renewable Sustainable Energy Reviews. 53, 1178, 2016. DOI: 10.1016/j.rser.2015.09.022

10. VERA S., SAUMA E. Does a carbon tax make sense in countries with still a high potential for energy efficiency? Comparison between the reducing-emissions effects

\begin{tabular}{|l|l|}
\hline \multicolumn{2}{|c|}{ A.5 macroscopic-closure \& market-clearing block } \\
\hline$X V_{i}=\frac{\lambda_{i}}{P Q_{i}}(S P+S G+\varepsilon S F)$ & (A.35) \\
\hline$Q_{i}=X P_{i}+X G_{i}+X V_{i}+\sum_{j} X_{i, j}$ & (A.36) \\
\hline$\sum_{i} L A B_{i}=T O T L A B$ & (A.37) \\
\hline$\sum_{i} C A P_{i}=$ TOTCAP & (A.38) \\
\hline
\end{tabular}

of carbon tax and energy efficiency measures in the Chilean case. Energy. 88, 478, 2015. DOI: 10.1016/j. energy.2015.05.067

11. LIU S.D., CHEVALLIER J., ZHU B.Z. Self-scheduling of a power generating company: Carbon tax considerations. Computer Operations Research. 66, 384, 2016. DOI: 10.1016/j.cor.2015.06.003

12. GERBELOVA H., AMORIM F., PINA A., MELO M., IOAKIMIDIS C., FERRAO P. Potential of $\mathrm{CO}_{2}$ (carbon dioxide) taxes as a policy measure towards low-carbon Portuguese electricity sector by 2050 . Energy. 69, 113, 2014. DOI: $10.1016 /$ j.energy.2014.01.011

13. CHEN C.C. An evaluation of optimal application of government subsidies on recycling of recyclable waste. Polish Journal of Environmental Studies. 14 (2), 137, 2005.

14. DI COSMO V., HYLAND M. Carbon tax scenarios and their effects on the Irish energy sector. Energy Policy. 59, 404, 2013. DOI: 10.1016/j.enpol.2013.03.055

15. MEYBODI M.A., BEHNIA M. Impact of carbon tax on internal combustion engine size selection in a medium scale CHP system. Applied Energy. 88 (12), 5153, 2011. DOI: 10.1016/j.apenergy.2011.07.025

16. SONG W., BI G.B., WU J., YANG F. What are the effects of different tax policies on China's coal-fired power generation industry? An empirical research from a network slacks-based measure perspective. Applied Energy. 142 (4), 2816, 2017. DOI: 10.1016/j.jclepro.2016.10.187

17. CANSINO J.M., CARDENETE M.A., ORDONEZ M., ROMAN R. Taxing electricity consumption in Spain: evidence to design the post-Kyoto world. Carbon Management. 7 (1-2), 93, 2016. DOI: 10.1080/17583004.2016.1178397

18. BJERTNAES G.H., FAEHN T., AASNESS J. Designing an electricity tax system in presence of international regulations and multiple public goals: An empirical assessment. Energy Policy. 36 (10), 3723, 2008. DOI: 10.1016/j.enpol.2008.06.032

19. LU X., TCHOU J., MC ELROY M.B., NIELSEN C.P. The impact of Production Tax Credits on the profitable production of electricity from wind in the US. Energy Policy. 39 (7), 4207, 2011. DOI: 10.1016/j.enpol.2011.04.034

20. CANSINO J.M., PABLO-ROMERO M.D., ROMAN R., YNIGUEZ R. Tax incentives to promote green electricity: An overview of EU-27 countries. Energy Policy. 38 (10), 6000, 2010. DOI: 10.1016/j.enpol.2010.05.055

21. CARBONE J.C., RIVERS N. The Impacts of Unilateral Climate Policy on Competitiveness: Evidence From 
Computable General Equilibrium Models. Review of Environmental Economics and Policy. 11 (1), 24, 2017. DOI: $10.1093 /$ reep/rew025

22. PUI K.L., OTHMAN J. Economics and environmental implications of fuel efficiency improvement in Malaysia: A computable general equilibrium approach. Journal of Cleaner Production. 156, 459, 2017. DOI: 10.1016/j. jclepro.2017.04.067

23. WU T., ZHANG M.B., OU X.M. Analysis of Future Vehicle Energy Demand in China Based on a Gompertz Function Method and Computable General Equilibrium Model. Energies. 7 (11), 7454, 2014. DOI: 10.3390/en7117454

24. KOLSUZ G., YELDAN A.E. Economics of climate change and green employment: A general equilibrium investigation for Turkey. Renewable Sustainable Energy Reviews. 70, 1240, 2017. DOI: 10.1016/j.rser.2016.12.025

25. RAMBERG D.J., CHEN Y.H.H., PALTSEV S., PARSONS J.E. The economic viability of gas-to-liquids technology and the crude oil-natural gas price relationship. Energy Economics. 63, 13, 2017. DOI: 10.1016/j.eneco.2017.01.017

26. LI W., JIA Z.J., ZHANG H.Z. The impact of electric vehicles and $C C S$ in the context of emission trading scheme in China: A CGE-based analysis. Energy. 119, 800, 2017. DOI: 10.1016/j.energy.2016.11.059

27. HANNUM C., CUTLER H., IVERSON T., KEYSER D. Estimating the implied cost of carbon in future scenarios using a CGE model: The Case of Colorado. Energy Policy. 102, 500, 2016. DOI: 10.1016/j.enpol.2016.12.046

28. ZHANG W., YANG J., ZHANG Z.Y., SHACKMAN J.D. Natural gas price effects in China based on the CGE model. Journal of Cleaner Production. 147, 497, 2017. DOI: 10.1016/j.jclepro.2017.01.109

29. BOHRINGER C., GARCIA-MUROS X., CAZCARRO I., ARTO I. The efficiency cost of protective measures in climate policy. Energy Policy. 104, 446, 2017. DOI: 10.1016/j.enpol.2017.01.007

30. LI W., JIA Z.J. The impact of emission trading scheme and the ratio of free quota: A dynamic recursive CGE model in China. Applied Energy. 174, 1, 2016. DOI: 10.1016/j. apenergy.2016.04.086

31. HE Y.X., LIU Y.Y., XIA T., DU M., GUO H.Z. The Optimal Price Ratio of Typical Energy Sources in Beijing Based on the Computable General Equilibrium Model. Energies, 7 (5), 2961, 2014. DOI: 10.3390/en7052961

32. HOSOE N. Estimation errors in input-output tables and prediction errors in computable general equilibrium analysis. Economic Modelling. 42, 277, 2014. DOI: 10.1016/j.econmod.2014.07.012

33. NATIONAL BUREAU OF STATISTICS (NBS). China Statistical Yearbook (2014). Available online: http://www. stats.gov.cn/tjsj/ndsj/ (accessed 04/2017).

34. CHINA INPUT-OUTPUT ASSOCIATION (CIOA). 2010 Input-Output Table. Available online: http://www.iochina. org.cn/Download/xgxz.html (accessed 04/2017).

35. WANG T., MA C., LIN C. SG-RAS /SG-CE Methods for SAM Balancing. Statistical Research. 29 (12), 88, 2012.

36. THE CENTRAL PEOPLE'S GOVERNMENT OF THE PEOPLE'S REPUBLIC OF CHINA. National Population Development Strategy Research Report. Available online: http://www.gov.cn/gzdt/2007-01/11/content_493677.htm (accessed 04/2017).

37. NATIONAL DEVELOPMENT AND REFORM COMMISSION (NDRC). Medium and long-term energy saving special planning. Available online: http://xwzx.ndrc. gov.cn/xwfb/200506/t20050628_104993.html (accessed 04/2017).

38. LIN B.Q., JIA Z.J. The energy, environmental and economic impacts of carbon tax rate and taxation industry: A CGE based study in China. Energy, 159, 558, 2018. DOI: 10.1016/j.energy.2018.06.167

39. PAO H.T., FU H.C., TSENG C.L. Forecasting of $\mathrm{CO}_{2}$ emissions, energy consumption and economic growth in China using an improved grey model. Energy. 40 (1), 400, 2012. DOI: $10.1016 /$ j.energy.2012.01.037 
